\title{
Applicability of mesopic factors to the driving task
}

\author{
RB Gibbons $\mathrm{PhD}^{\mathrm{a}}$, $\mathbf{T}$ Terry ${ }^{\mathrm{a}}$, R Bhagavathula ${ }^{\mathrm{a}}$, $\mathbf{J}$ Meyer ${ }^{\mathrm{a}}$ and A \\ Lewis b
}

\author{
${ }^{a}$ Virginia Tech Transportation Institute, Blacksburg, Virginia, \\ USA \\ ${ }^{\mathrm{b}}$ Carlisle, Massachusetts, USA
}

Short title: Application of mesopic factors to driving

Received 13 November 2015; Revised 25 November 2015; Accepted

With the advent of light-emitting diode technology being applied to roadway lighting, the spectral power distribution of the light source is becoming much more important. In this experiment, the detection of pedestrians at five adaptation levels under three light sources, high pressure sodium and light emitting diodes of two color temperatures, was measured in realistic roadway scenarios. The results show that while the light source type was not significant, an increase in adaptation luminance also increased the detection distance. As the offset of the object to the roadway increased, some spectral effects became more significant; however, this effect was not consistent across all angles of eccentricity. The conclusions from this work indicate that mesopic factors may not be applicable on high-speed roads.

Address for correspondence: Ronald B Gibbons, Virginia Tech Transportation Institute, 3500 Transportation Research Plaza, Blacksburg, VA 24061, USA

E-mail: rgibbons@vtti.vt.edu 


\section{Introduction}

Traditional roadway lighting utilizes high-pressure sodium (HPS) light sources. This source provides a high photometric efficacy. With the advent of light-emitting diode (LED) technology being applied to roadway lighting, a new aspect of the light source is being considered, that of the spectral power distribution (SPD). This change in technology, along with the development of the mesopic adaptation model by the International Commission on Illumination (CIE) ${ }^{1}$, has the potential to reduce lighting on roadways while maintaining the same levels of safety. The mesopic adaptation model, however, was developed primarily in the laboratory, in simulators, or using a very specific geometry on roadways ${ }^{2-8}$. This project investigates the applicability of the mesopic adaptation model to actual driving conditions.

In this experiment, which was performed on a full scale roadway that was closed to traffic, the detection of small objects and pedestrians on the roadway and along the edge of the roadway was measured. Three different light sources, including HPS and two LED sources of different colour temperatures, were used for the overhead lighting. Five different adaptation levels were used and the vehicle speed was varied. In all, 36 participants were included in each of the experiments. Participants each returned for three separate nights to perform the detection tasks under each light source. The luminance of the detected objects and its background were also measured for each experimental condition.

\section{Research objectives}

The research objectives of this experiment are to

- Evaluate the impact of the spectra of overhead lighting systems on driver visual performance.

- Evaluate the applicability of mesopic models and scaling factors to a roadway lighting design.

\section{Experimental method}

This experiment was conducted on a closed-road facility where an experimental lighting and control system were available to measure the effect of the spectral component of the lighting system.

\subsection{Facilities and equipment}

\subsubsection{Smart Road}

The research was conducted on the Smart Road at the Virginia Tech Transportation Institute (VTTI). The Smart Road is a $3.5 \mathrm{~km}$ (2.2 mile), restricted-access test track with guard rails, pavement markings, and a variety of overhead lighting installations. The Smart Road has two pavement surfaces, asphalt and concrete, and overhead lighting 
levels can be adjusted to match luminance levels between lighting types as required. The general layout of the Smart Road is shown in Figure 1

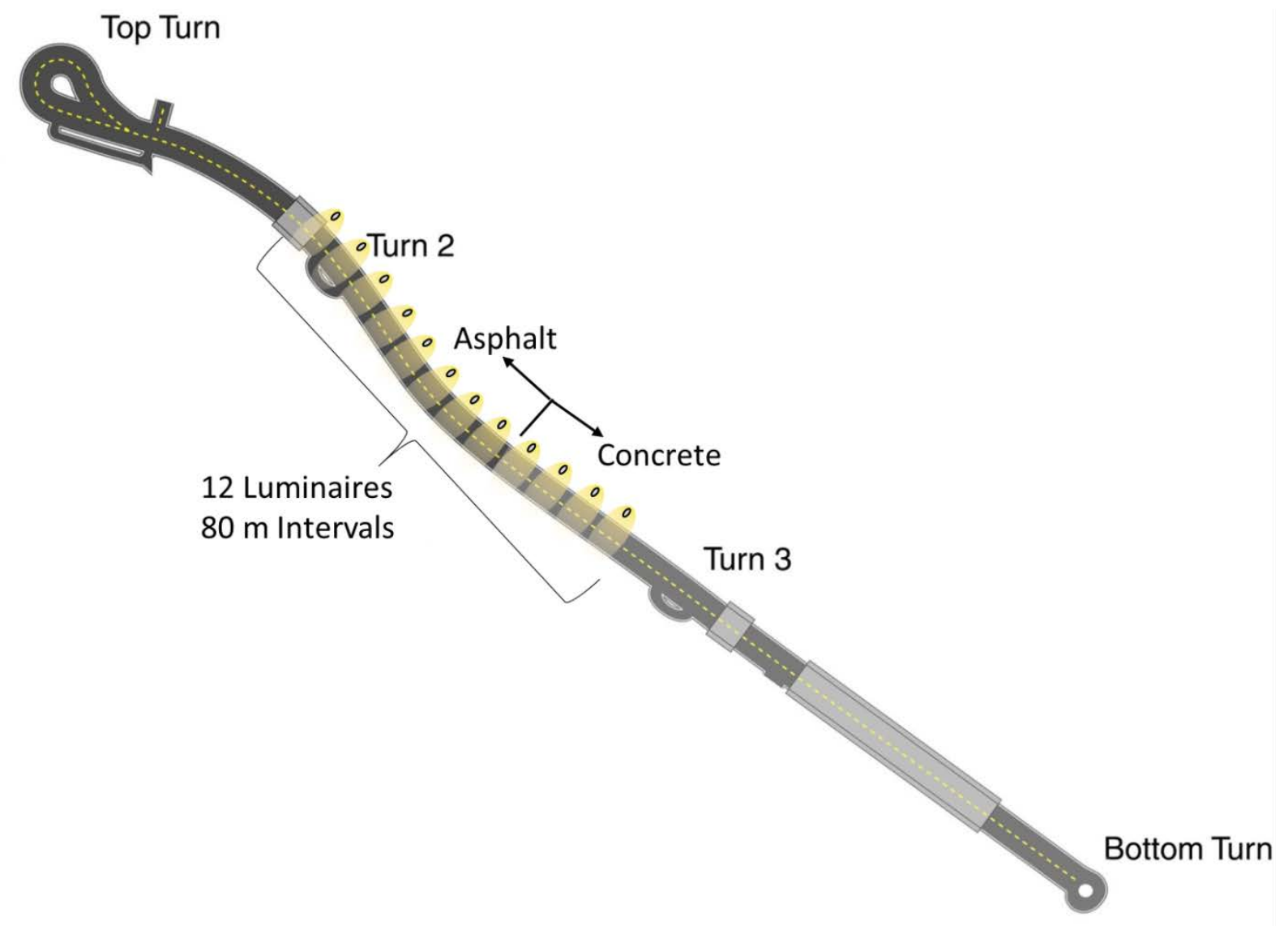

Figure 1. Smart Road test track.

Seven different locations were used for the pedestrian locations, four in one direction and three in the other. The pedestrian locations were also split with four in the asphalt section and three in the concrete section of the roadway.

\subsubsection{Vehicles and headlamp systems}

Two sport-utility vehicles (SUVs) were used in the study, a 1999 Ford Explorer and a 2000 Ford Explorer, with the same body style and internal layout. Both were instrumented with digital audio and video recorders, luminance cameras, small monitors, and keyboards. The data collected included driving distance, vehicle speed, global positioning system (GPS) location, and a user-input button used to calculate detection and color-recognition distances. During the experiments, the rearview and side mirrors were covered to prevent headlamp glare from the other test vehicle.

High-intensity discharge (HID) headlamps were installed on the test vehicles. The headlamps selected were Hella $90 \mathrm{~mm}$ Bi-Xenon projector lamps with a single 1-F capacitor-stabilized headlamp input voltage on each vehicle. Only low beams were used. 
Before each night of experiments, the headlamps were aligned according to manufacturer specifications.

\subsection{Experimental design}

A $2 \times 3 \times 5 \times 2 \times 4 \times 2$ mixed-factors experiment was designed to measure the effect of age, overhead lighting type, adaptation luminance, vehicle speed, visual angle, and pedestrian position on pedestrian detection distances. This was a full factorial experiment with the exception of two combinations that was not able to be achieved ( $8.9 \mathrm{~m}$ offset and $0.1 \mathrm{~cd} / \mathrm{m}^{2}, 8.9 \mathrm{~m}$ offset and $0.5 \mathrm{~cd} / \mathrm{m}^{2}$ ). Additionally, the luminance contrast of the pedestrians was measured and used as a covariate in the analysis. The dependent variable for the experiment was pedestrian detection distance. The independent variables used in the experiment are listed in Table 1.

\subsection{Independent variables}

\subsubsection{Age}

Participants were divided into two age groups: younger drivers (25-35 years old) and older drivers ( 65 years old and older). The age range provides a broad range of driving experience as well as physiological changes in drivers' visual capabilities.

\subsubsection{Overhead lighting type}

For this project, three lighting systems installed on the Smart Road were used. One was a traditional HPS system and two were solid state LED systems (correlated colour temperatures (CCT) (3500 and $6000 \mathrm{~K}$ ). Each of the lighting systems was equipped with a wireless control system to provide dimming and on-off control for the luminaires. All luminaires were mounted $15 \mathrm{~m}$ (49 ft) high and spaced $80 \mathrm{~m}(262 \mathrm{ft})$ apart.

\subsubsection{Adaptation luminance}

Adaptation luminance was the luminance, viewed from inside the test vehicle, for a given combination of overhead lighting level and pavement type. The adaptation luminances for the different combinations are given in Table 2. It is noteworthy that there was a common adaptation level between the two pavements types at $0.35 \mathrm{~cd} / \mathrm{m}^{2}$.

\subsubsection{Speed}

The participants drove the vehicle at $56 \mathrm{~km} / \mathrm{h}$ (35 mph) and $80 \mathrm{~km} / \mathrm{h}$ (50 mph).

\subsubsection{Pedestrian offset}

To create the possibility for peripheral detection, pedestrians were placed at four offsets with respect to the travel lane. To determine the pedestrian positions, a theoretical detection distance was fixed at $83 \mathrm{~m}\left(277 \mathrm{ft}\right.$.) based on a $1^{\circ}$ downward viewing angle with a vehicle height of $1.45 \mathrm{~m}^{5}$. Four offsets were calculated based on detection from that distance - 3.0, 7.7, 8.9, and $21.0 \mathrm{~m}(9.8,25,29$, and $69 \mathrm{ft})$ - and are shown in Figure 2. 
All seven pedestrian positions were located in the lighted section of the Smart Road, and all pedestrian positions had a vertical illuminance on the pedestrian's face as similar as possible to each other within a specified lighting condition.

\subsubsection{Pedestrian on left or right}

The pedestrian stood on the left or right side of the road with respect to the participant vehicle. Pedestrians at the $3.0 \mathrm{~m}(9.8 \mathrm{ft})$ offset were located on both sides of the road. Pedestrians at $7.7 \mathrm{~m}(25 \mathrm{ft})$ offset were located only on the left side of the road, and pedestrians at the $8.9 \mathrm{~m}(29 \mathrm{ft})$ and $21.0 \mathrm{~m}$ (69ft) offset were located only on the right side of the road, as shown in Figure 2.

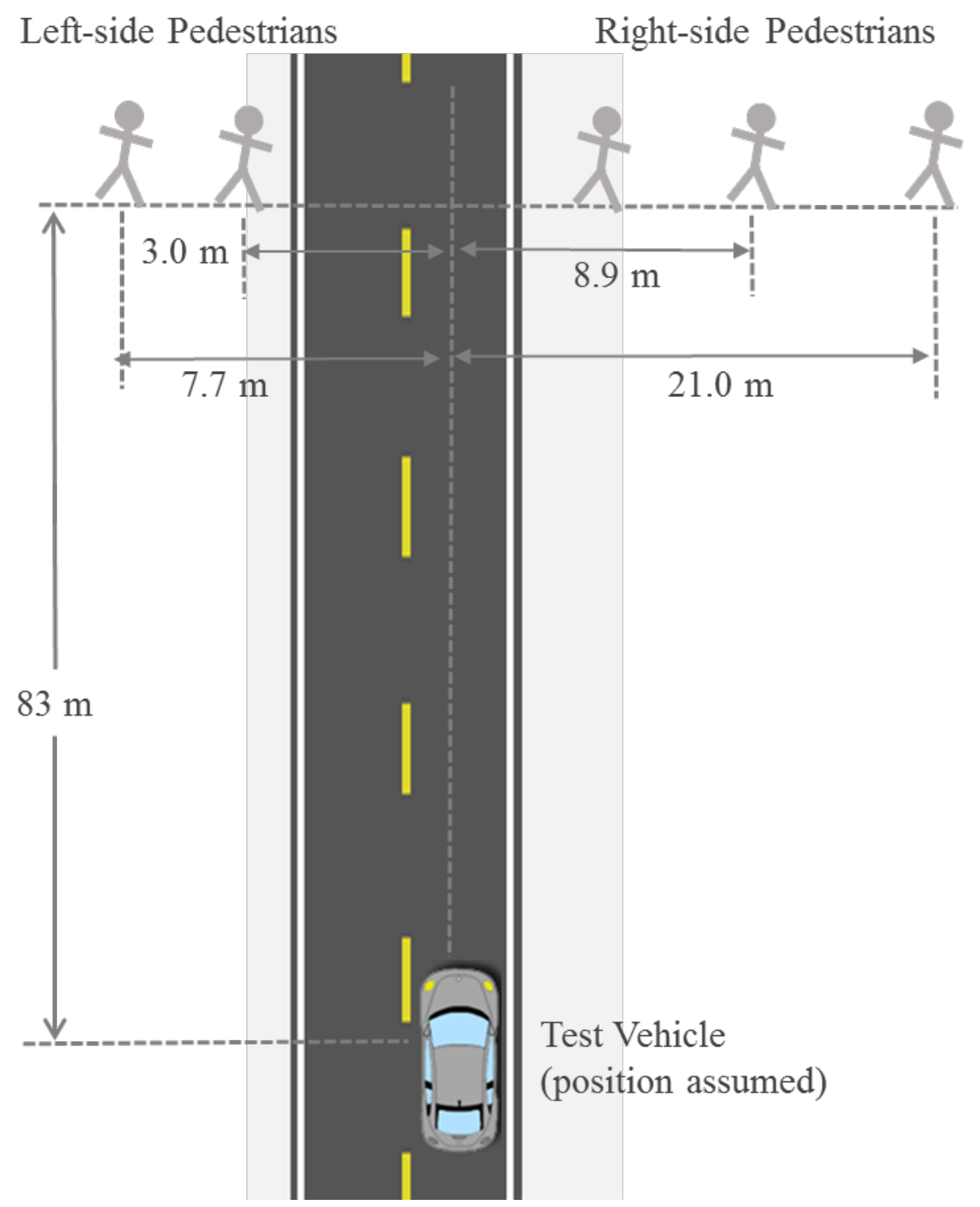

Figure 2. Pedestrian positions and offsets from the roadway. 
As mentioned, there were seven pedestrian locations that were used on the road. Due to some limitations of roadway geometry and the areas adjacent to the roadway not all offsets were available at all locations. As such not all of the combinations of adaptation level and pedestrian offset were able to be achieved. In particular, the two combinations of $8.9 \mathrm{~m}$ offset and $0.1 \mathrm{~cd} / \mathrm{m}^{2}$ and $8.9 \mathrm{~m}$ offset and $0.5 \mathrm{~cd} / \mathrm{m}^{2}$ were not tested.

\subsection{Covariate}

The luminance of the pedestrians and the background behind them was measured using a calibrated imaging photometer system (ProMetric PM-9913E-1, Radiant Imaging ${ }^{\circledR}$, Redmond, WA) from $83 \mathrm{~m}$ (277 ft.). The Weber contrast was calculated from that measurement using analysis software that displayed the captured image, allowing the user to select an area of interest and then calculate the luminance of that area of interest. Multiple areas of interest were selected to calculate luminance contrast.

\subsection{Dependent variable}

The detection distance was the distance at which a participant was able to detect the presence of an on- or off-axis pedestrian. To measure detection distance, researchers instructed participants to say "person" or "pedestrian" when they first saw the pedestrian. At that moment, an in-vehicle experimenter pressed a button to flag the data. The invehicle experimenter also pressed a button to flag the data when the vehicle passed the pedestrian. If a participant failed to see a pedestrian, it was counted as a miss. Later analysis calculated the distance between these two points to determine the detection distance.

\subsection{Participants}

A total of 36 participants performed the experiment, 18 older and 18 younger. Within each age group, participants were divided equally by gender. Mean and standard deviation of participant age, visual acuity, mesopic visual acuity, and low-contrast visual acuity are listed in Table 3.

\subsection{Procedure}

Participants were recruited, screened, and directed to the Smart Road. Each participant attended three experimental sessions, one for each type of overhead lighting. Each session consisted of one practice run and 12 experimental laps (2 lengths) on the Smart Road, for a total of 24 trials for each lighting type. Lighting level was changed twice during each session, so all three intensities were tested. Two participants in two vehicles typically completed the experiment at one time. The order in which the overhead lighting type and the adaptation luminances were experienced were counterbalanced using a Latin squares approach for each of the participant pairings. 
With the seven potential object locations there were a total of 84 potential target presentations per overhead lighting type. Typically only three pedestrian presentations were made per lap. The pedestrian presentation was also counter balanced using a Latin Squares approach using blank catch trials for locations where the object was not presented.

During the experiment, the vehicles drove through the test section of the road one at a time, pausing at one of the turnarounds while the other vehicle completed its lap, so that the two vehicles would not interfere with each other. Participants completing experimental laps would state when they saw a pedestrian. The researcher recorded the detections with a button press, as described earlier. The in-vehicle researcher ensured that the participant was driving safely and at the correct speed. For safety reasons, when using confederate pedestrians, after the participant saw the pedestrian, the researcher radioed the pedestrian with instructions to move away from the road.

\subsection{Data analysis procedures}

\subsubsection{Detection distances}

The detection distances were reduced from the data stream provided by the instrumentation system in the vehicle. The points of detection and where the vehicle passed the object of interest were recorded based on the in-vehicle experimenter's button presses. All moments of detection and recognition were also verified by examining video data. Video verification is more precise because it removes any delay caused by an experimenter's reaction time. Once the positions were verified, GPS coordinates were recorded and the detection distances were calculated. The button presses are accurate to within 100 milliseconds (ms) and logged to a data file. The vehicle's GPS coordinates were accurate to within $5 \mathrm{~cm}$ (2 in).

After video data reduction, an analysis of variance (ANOVA) was used to determine if the independent variables significantly affected pedestrian detection. For significant effects, post hoc analyses were performed using, Tukey honestly significant difference (HSD) tests.

An analysis of covariance (ANCOVA) using pedestrian contrast as a covariate was performed to determine the relationship between contrast and detection distance. Only luminance contrast was measured.

\section{Results}

\subsection{ANOVA results}

The significant effects in the ANOVA analysis are shown in Table 4 (for brevity the entire ANOVA results table is not shown). It is noteworthy that the main effect of overhead lighting type was not significant for this comparison.

\subsubsection{Main effect - Adaptation luminance}


The results for adaptation luminance's effect on mean detection distances are shown in Figure 3 (the error bars (however small) on the figure depict the standard error of the mean). It was found that adaptation luminance significantly affected detection distance, with a general trend of higher adaptation luminances having longer detection distances.

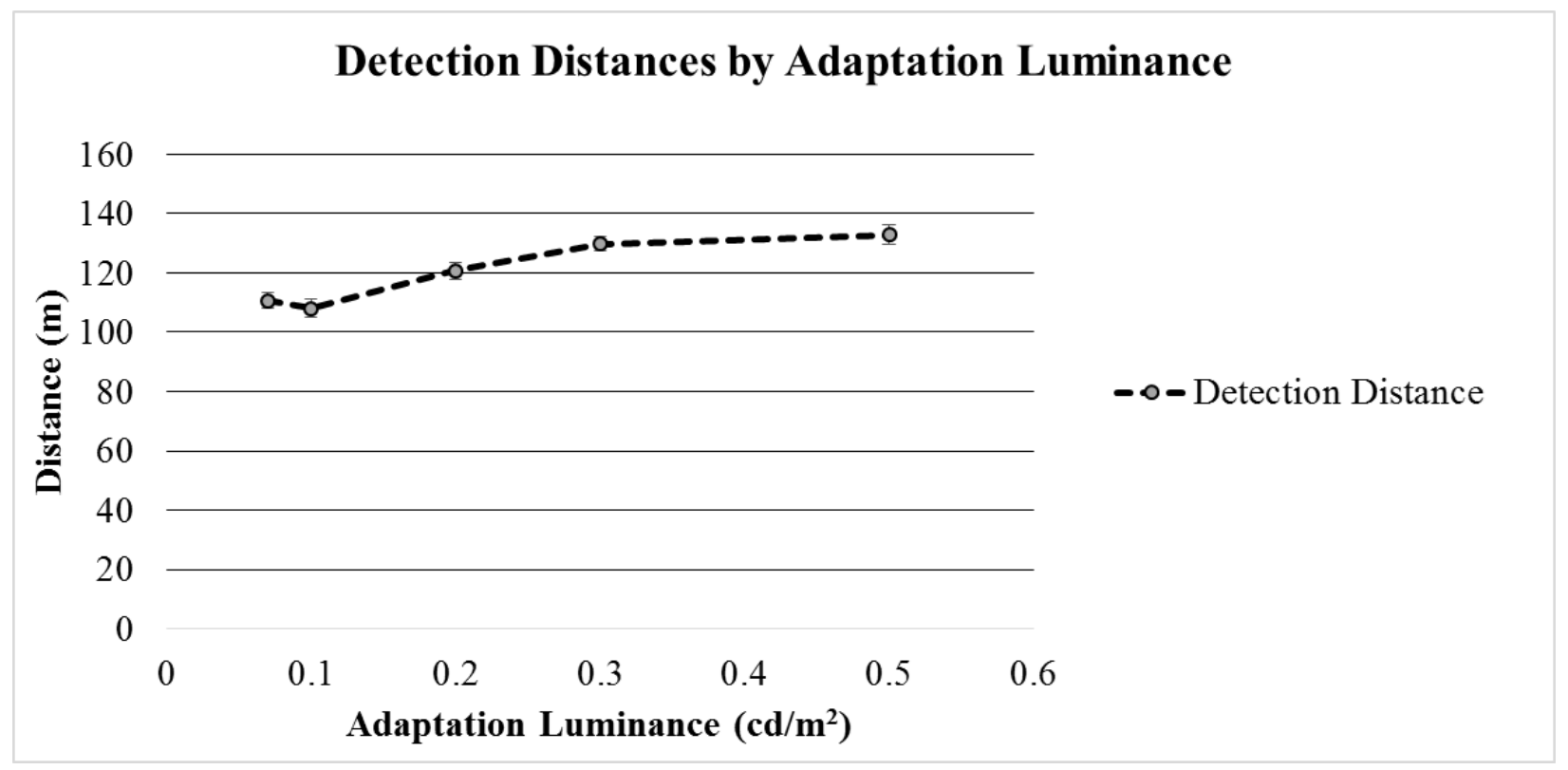

Figure 3. Mean detection distance plotted against adaptation luminance. Error bars denote standard error of the mean.

\subsubsection{Main effect - Age}

Age significantly affected pedestrian detection distance. The mean detection distance for older participants $(M=107 \mathrm{~m}$ (351 ft)) was significantly shorter than that for younger participants $(M=135 \mathrm{~m}(440 \mathrm{ft}))$. This difference is expected based on the results from participants' visual tests. The Snellen visual acuity test performed during participant screenings found that older participants had poorer visual acuity than younger participants. While normal vision is 20/20, younger participants had an average visual acuity of 20/17.2, while older participants had an average visual acuity of 20/21.6. Older participants also had poorer contrast sensitivity than younger participants. When the contrast sensitivity exam was administered with lighter-coloured gray letters on the Snellen eye chart, younger participants had an average acuity of 20/20.8, while the older participants had an average of 20/27.8. These two exams were performed in photopic conditions. A third Snellen acuity test was performed in mesopic conditions; for that exam, younger participants had an average visual acuity of 20/25.7, while older participants had an average visual acuity of 20/38.1. As the difficulty of the Snellen eye examinations increased, from normal to low contrast to mesopic conditions, older participants' visual acuity decreased when compared to that of the younger participants.

\subsubsection{Two-way interactions - Offset and adaptation luminance}


There were a number of statistically significant and marginally significant twoway effects on detection distance. As the interest of this paper is primarily in the impact of light source spectrum, the discussion of these factors will be limited.

The combination of adaptation luminance and offset affected detection distance as is shown in Figure 4. At an adaptation luminance of $0.07 \mathrm{~cd} / \mathrm{m}^{2}$ the detection distances decreased with increasing offset. This is to be expected, given that visual acuity worsens as eccentricity increases, and if drivers' eyes were focused on the roadway, a higher offset would correspond to higher eccentricity. At higher adaptation luminances, however, the relationship between offset and detection distance changed and was less clear and more varied. This finding is important in that an expectation of the mesopic process is that the differences in the periphery would not be as significant at lower adaptation levels as the rods would be more active in this region.

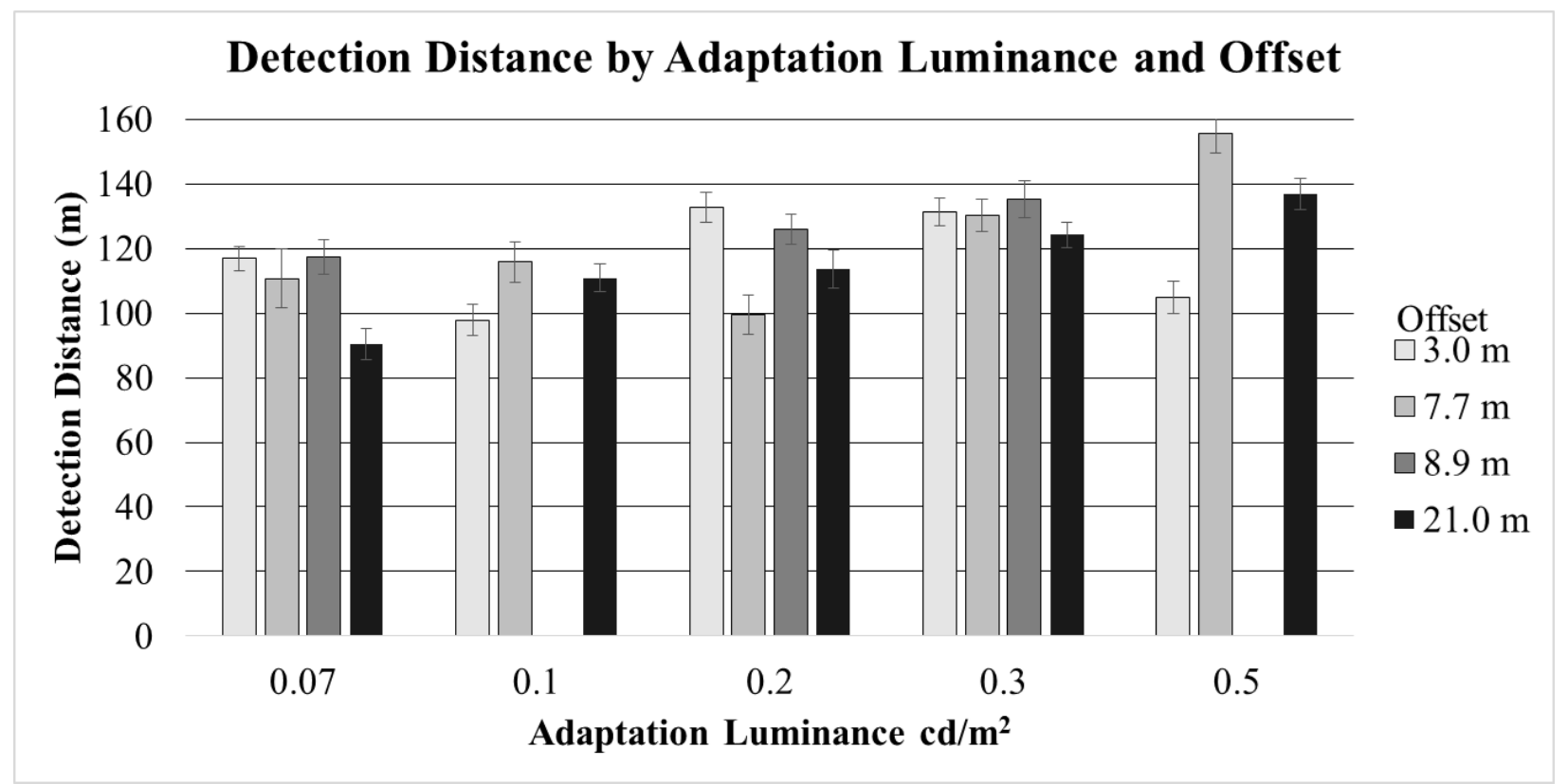

Figure 4. Mean detection distance plotted against adaptation luminance and offset. Error bars represent standard error. (Note: two conditions are missing due to limitations of the experiment environment).

\subsubsection{Two way-interactions - Offset and speed}

Mean detection distances were longer for higher speeds at 3.0 and $21.0 \mathrm{~m}$ (9.8 and $69 \mathrm{ft}$ ) offsets ( 2 and 14 degrees at $83 \mathrm{~m}(277 \mathrm{ft})$ ), but detection distances were shorter for higher speeds at 7.7 and $8.9 \mathrm{~m}$ (25 and $29 \mathrm{ft}$ ) offsets (5 and 6 degrees at $83 \mathrm{~m}(277 \mathrm{ft})$ ) (Figure 5). Some explanation for this could stem from roadway design, driving speed, and scanning behavior. At faster speeds, drivers are likely to be more vigilant and might have different scanning behaviour. Roads with $56 \mathrm{~km} / \mathrm{h}$ (35 mph) speed limits are narrower; pedestrians can appear on both sides of the road, and drivers have more time to respond to hazards, so scanning is more likely to occur at larger angles to both the left and right. Roads with $80 \mathrm{~km} / \mathrm{h}$ (50 mph) speed limits are more likely to be divided and/or have fewer pedestrians. Although drivers might be more vigilant, scanning might be restricted to within a few degrees of the roadway on the left but cover a broader angle on 
the right, or rely more on peripheral vision. Therefore, at higher speeds, more vigilant drivers would detect pedestrians from farther away within their region of vigilant scanning, perhaps 2 degrees left to 14 degrees right, corresponding to $3.0 \mathrm{~m}$ and $21.0 \mathrm{~m}$ offsets from a distance of $83 \mathrm{~m}(277 \mathrm{ft})$, respectively.

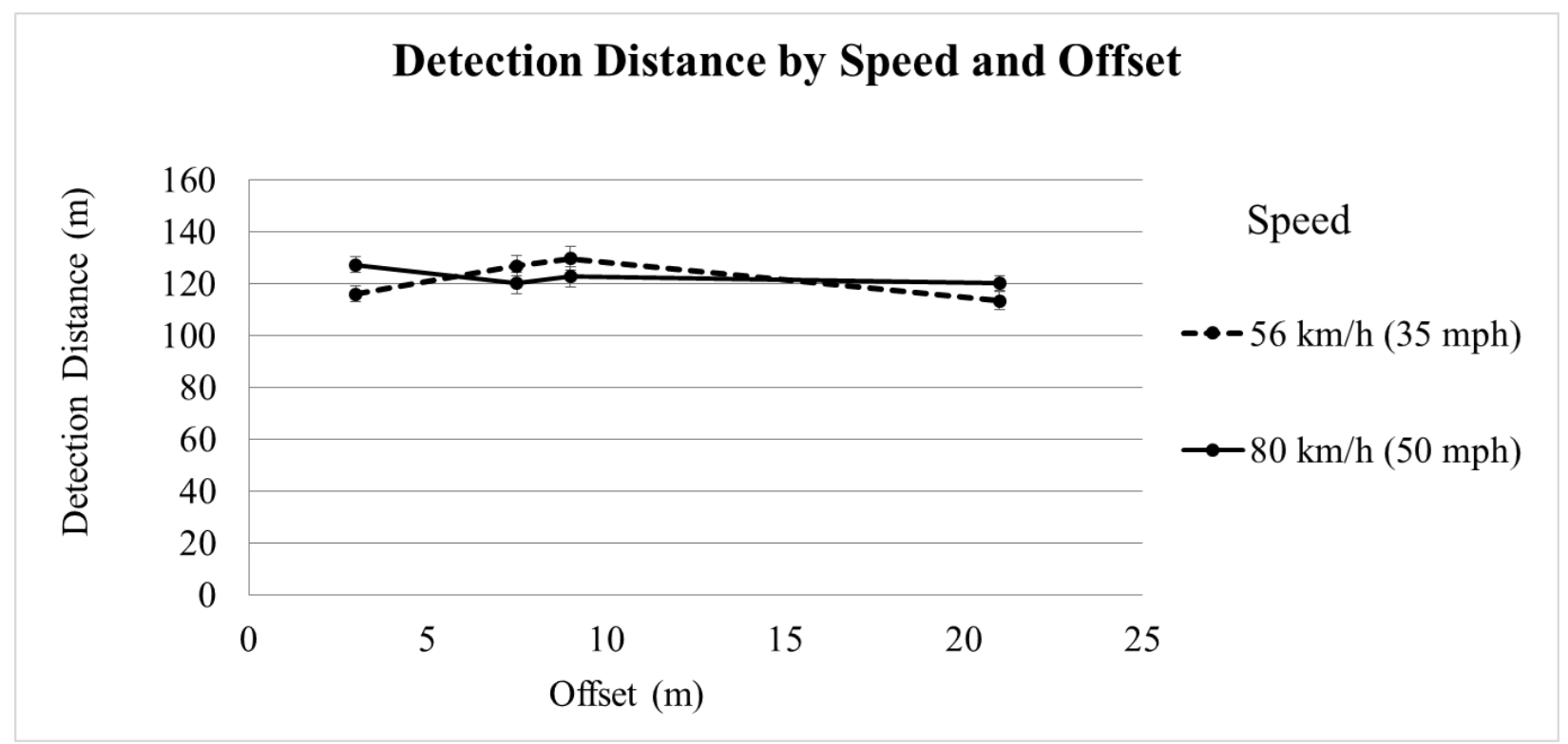

Figure 5. Mean detection distance plotted against speed and offset. Error bars represent standard error of the mean.

\subsubsection{Three-way interactions}

When considering the three way interactions, there are no clear trends in the impact of adaptation luminance for the interactions with offset, age and speed. One three way interaction of interest however is the one involving overhead lighting type, speed and age as shown in Figure 6. Here, the age impact was as expected, the older participants performed at a lower level than the younger participants. The HPS luminaire out-performed the other luminaire types for both ages and seemed to be affected by the speed. The 3500K LED performed at a lower level but was affected by speed. The item of interest here is the impact of the 6000K LED. For the older participants, the mean detection distance was not affected by speed. However, for the younger participants it was. This result may indicate one of two things both related to the typically yellowing of the lens in the older driver's eye. The additional short wavelengths reaching the retinas of the younger participant's eyes may have provided a higher degree of glare with the scan pattern chosen for the slower speed but this might be blocked by the lens of the older participant. Similarly the enhanced short wavelengths in the 6000K LED for the older driver may overcome the limitations of the older lens and provide higher performance for the older driver. 


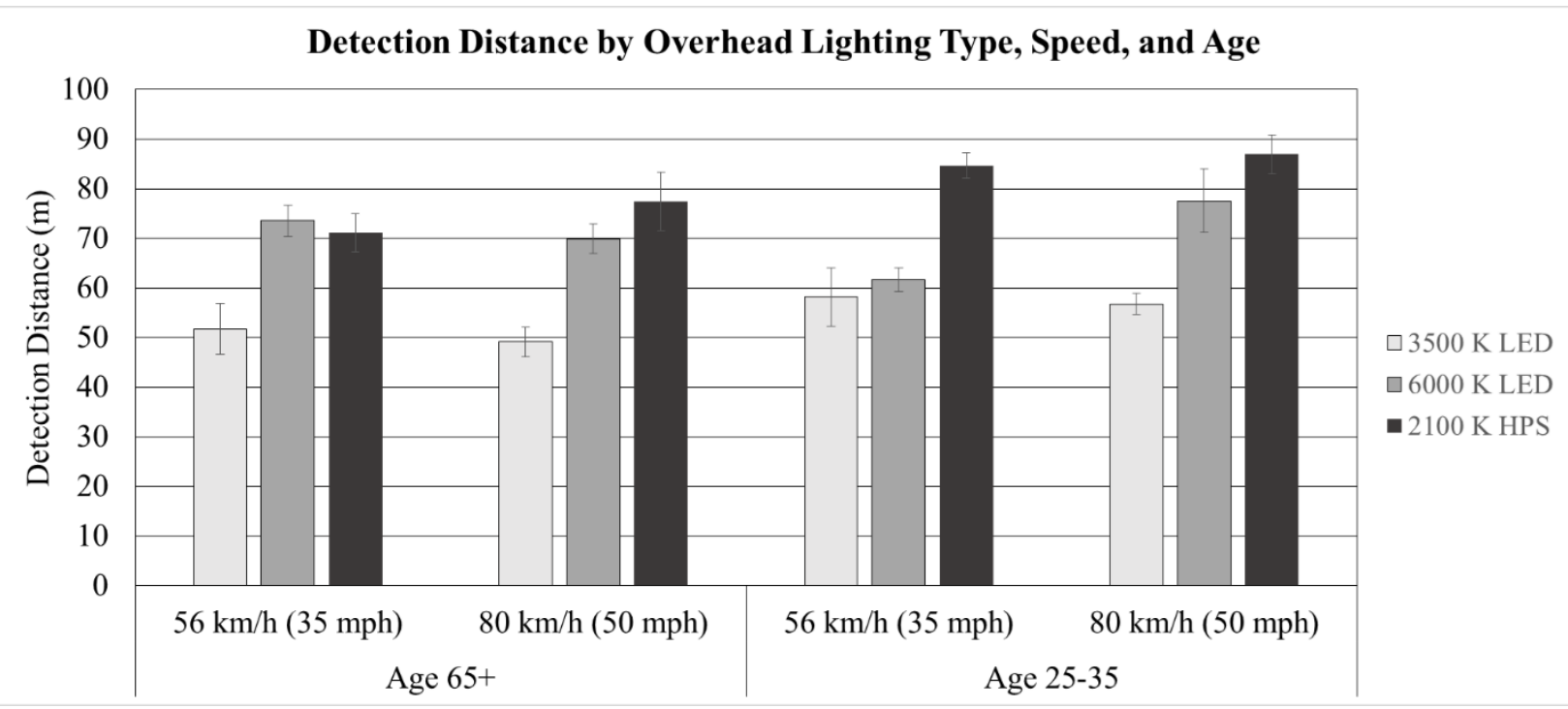

Figure 6. Mean detection distance for the three way interaction of overhead lighting, speed and age. Error bars represent standard error of the mean.

\subsubsection{Other interactions of interest}

There are two other interaction of interest to be considered. Neither of these is statistically significant but they are of interest for the purposes of the experiment. These two interactions are overhead lighting type by offset and overhead lighting type by adaptation luminance.

Overhead lighting type by offset

The interaction effect between overhead lighting type and offset was not statistically significant; however, there were differences in mean detection distances among the overhead lighting types that depended on offset. At the $3.0 \mathrm{~m}(9.8 \mathrm{ft})$ and 7.7 $\mathrm{m}(25 \mathrm{ft})$ offsets, the overhead lighting types had similar detection distances. At the $8.9 \mathrm{~m}$ $(29 \mathrm{ft})$ and $21.0 \mathrm{~m}(69 \mathrm{ft})$ offsets, the $6000 \mathrm{~K}$ LED lighting had greater detection distances, possibly because the $6000 \mathrm{~K}$ LED lighting's spectral distribution is more efficient in the mesopic range, and mesopic effects are only seen in the periphery. At the $21.0 \mathrm{~m}$ (69 ft) offset, the lighting types' mean detection distances increased with increasing correlated colour temperature. The results are illustrated in Figure 7. 


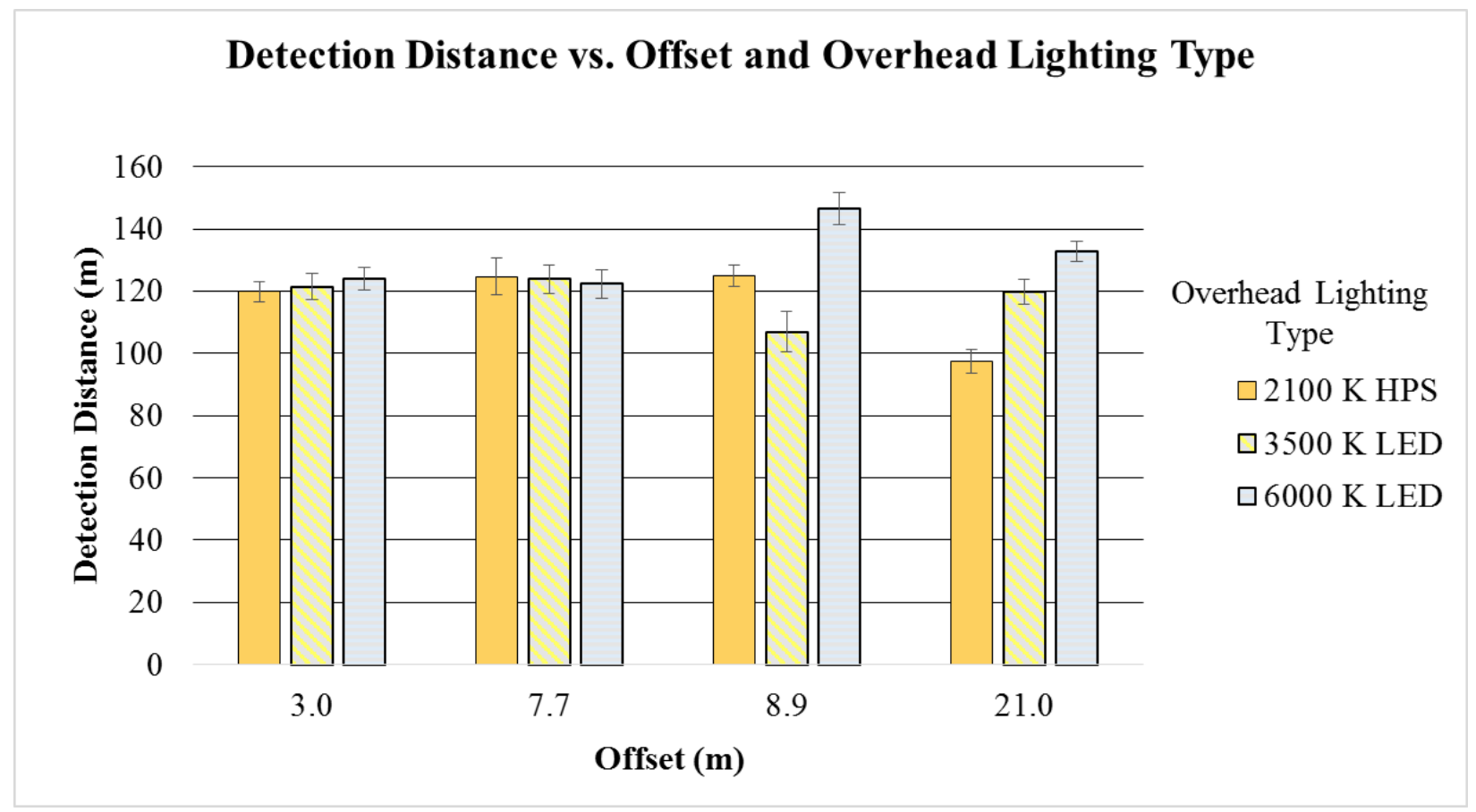

Figure 7. Mean detection distance by offset and overhead lighting type. Error bars represent standard error.

Overhead lighting type and adaptation luminance

To isolate the effects of overhead lighting and adaptation luminance, Figure 8 shows their combined effect on mean detection distance. Figure 7 shows that overhead lighting with a higher CCT and with a more-efficient spectral power distribution in the mesopic range had longer detection distances, but only at larger eccentricities, where mesopic effects are expected. One would also expect higher adaptation luminances to correlate with longer detection distances for large-object detection because the general environment is brighter. However, that effect was only seen for the LED lighting; at adaptation luminances of 0.07 and $0.1 \mathrm{~cd} / \mathrm{m}^{2}$, detection distances for the LED lighting types were shorter than for adaptation luminances of $0.2 \mathrm{~cd} / \mathrm{m}^{2}$ and higher. It is important to note here that the vehicle headlamps were turned on at all times in the experiment. There is the potential here for a significant interaction of the headlamps and the overhead lighting. The driver may never be fully adapted to the overhead lighting system because the headlamp illumination may dominate the effect. As a result, the impact of the overhead lighting spectrum and the adaptation luminance would be minimized. 


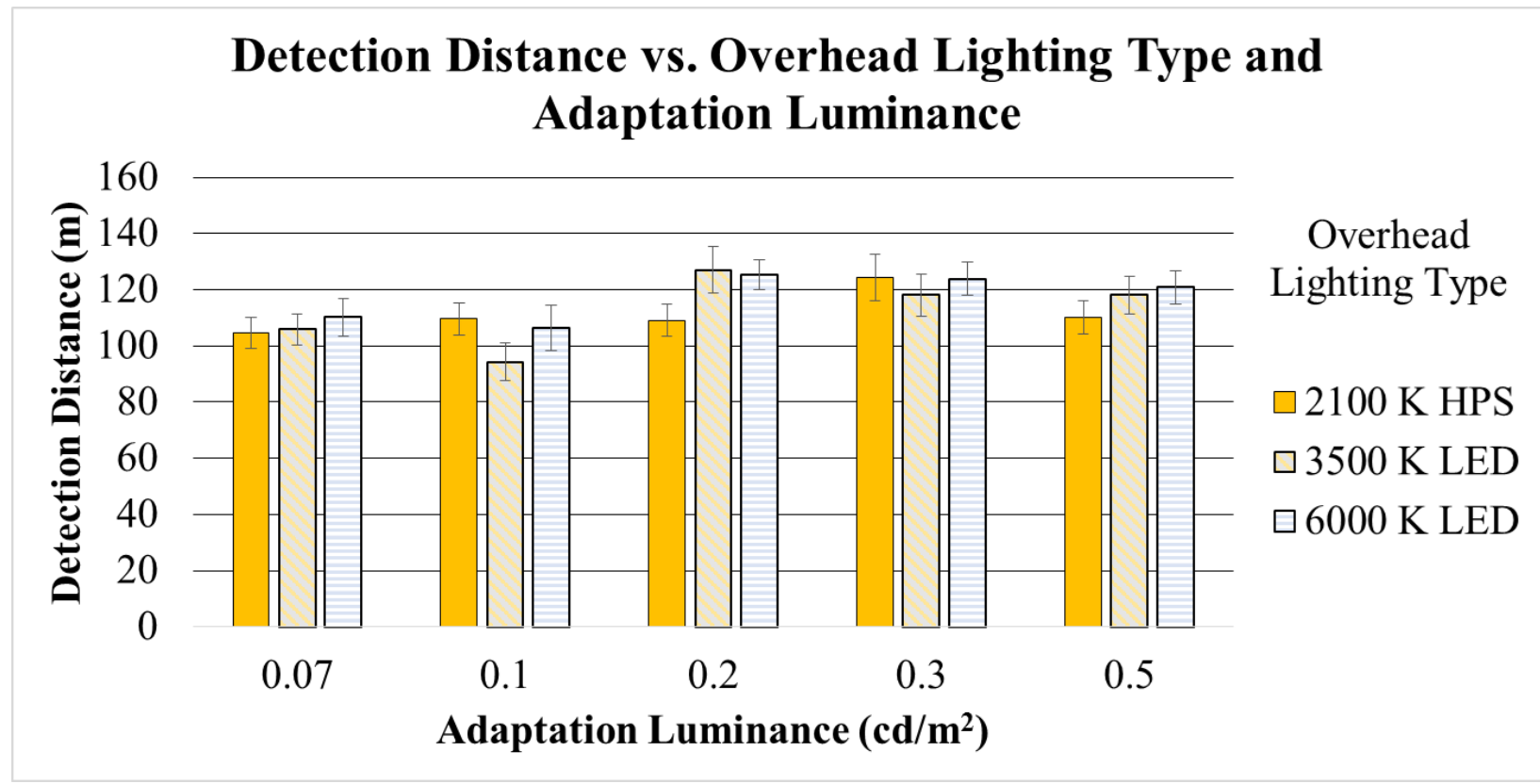

Figure 8. Mean detection distance by adaptation luminance and overhead lighting type. Error bars represent standard error of the mean.

\subsection{Contrast and detection distance}

The ANCOVA for detection distance results with contrast as a covariate was calculated. The significant $(p<0.05)$ results are listed in Table 5. Each of the statistically significant factors is discussed below the table.

\subsubsection{Adaptation luminance}

The detection distance at $0.1 \mathrm{~cd} / \mathrm{m}^{2}$ was lower than at the other adaptation luminances, and the Weber contrast results could explain why. At $0.1 \mathrm{~cd} / \mathrm{m}^{2}$, the pedestrian was seen in positive contrast, but at all the other adaptation luminance levels the contrast was negative, as illustrated in Figure 9. At some point, when the vehicle approached the pedestrian, the pedestrian contrast passed from negative to positive. Detection is much more difficult as contrast passes through zero, causing shorter detection distances. 


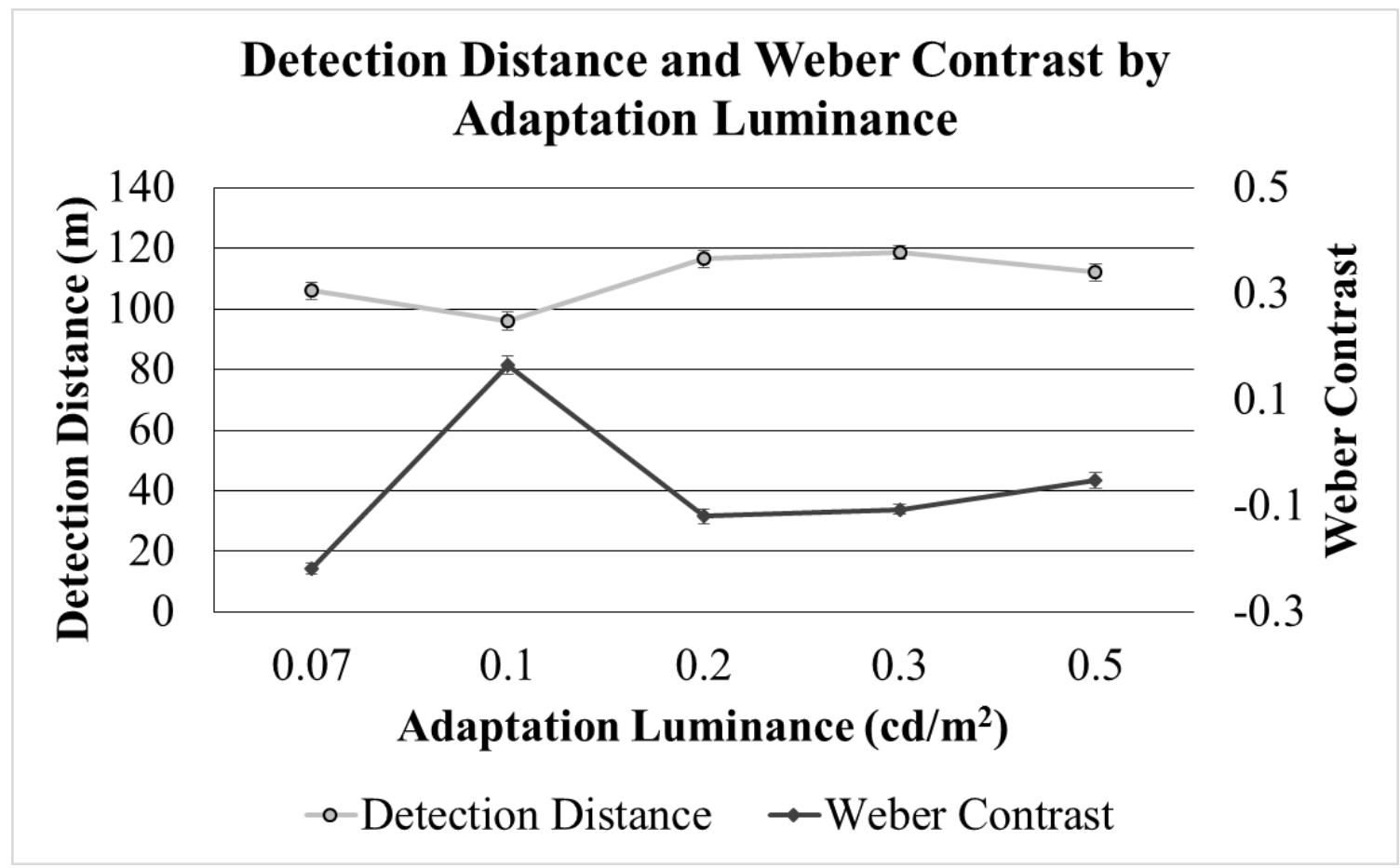

Figure 9. Mean detection distance and Weber contrast plotted against adaptation luminance. Error bars represent standard error of the mean.

\subsubsection{Offset}

As offset increased, contrast approached zero and detection distance decreased (Figure 10). There was a sharp increase in contrast and the contrast passed through zero

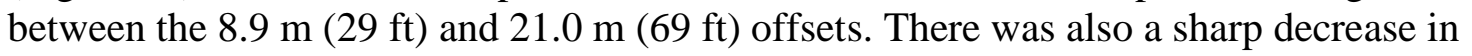
detection distance between the $8.9 \mathrm{~m} \mathrm{(29} \mathrm{ft})$ and $21.0 \mathrm{~m}(69 \mathrm{ft})$ offsets. Contrast polarity factor $\left(\mathrm{C}_{\mathrm{FP}}\right)$, as described by Adrian, shows that objects in negative contrast are easier to detect than those in positive contrast. ${ }^{9}$ In this experiment, the contrast at the $21.0 \mathrm{~m}$ (69 $\mathrm{ft}$ ) offset was positive, but at the other offsets the contrast was negative. That could help explain why detection distances were so much shorter at the $21.0 \mathrm{~m}(69 \mathrm{ft})$ offset than at the other offsets, even though the contrast at the $21.0 \mathrm{~m}(69 \mathrm{ft})$ offset was close to 0.1 .

Probability summation, or the probability of detecting an object with both eyes, cannot be factored into the visibility of pedestrians at the various offsets due to this study's lack of control over participants' eye-gaze behavior, and offsets did not necessarily correspond to eccentricity. 


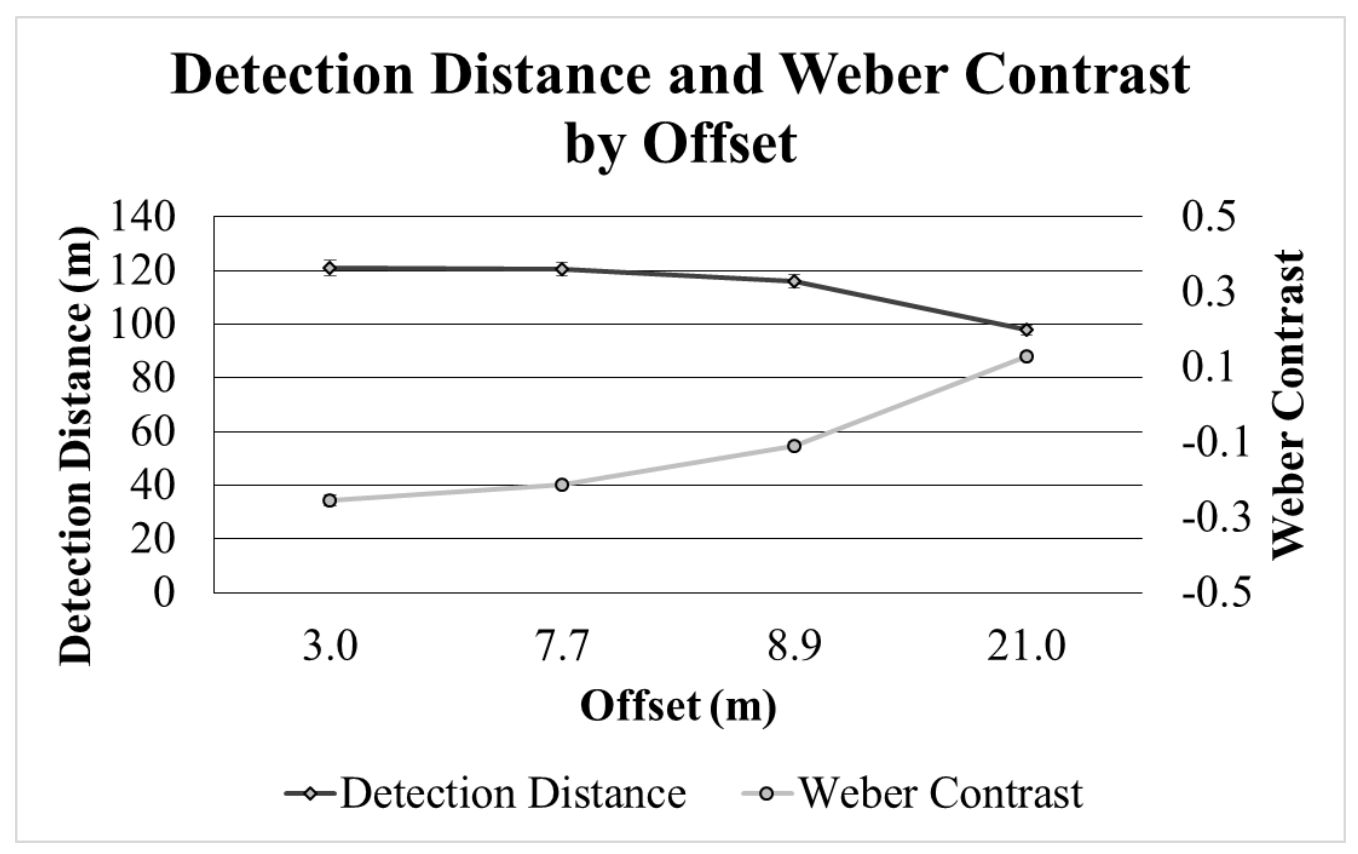

Figure 10. Mean detection distance and Weber contrast plotted against offset. Error bars represent standard error of the mean.

\section{Discussion}

This experiment showed some significant results although they may be counter to some expectations. This experiment simulated a real-driving scenario on a full-scale roadway. In this experiment, the two primary goals of studying the impact of the light source spectrum and the applicability of the mesopic models were investigated.

This experiment found no significant differences in detection distances between overhead lighting type at any offset, although results showed a trend toward longer detection distances with $6000 \mathrm{~K}$ LED lighting at greater offsets. The results do not strongly support a spectral effect of overhead lighting on mesopic visibility in the periphery. That result differs from what has been reported in the literature previously mentioned. It is important to point out that the geometry in this experiment was not fixed. The objects appeared along the roadway as they would in a real-life driving situation, and drivers depended on glance patterns to scan their driving environment and detect peripheral objects. Therefore, they likely detected objects in the fovea, where mesopic effects do not occur.

Another aspect of this is the presence of the headlamps on the vehicle. With the presence of headlamps, the adaptation luminance of the driver's eye is likely not significantly impacted. As a result, the spectral power distribution of the overhead lighting type is likely not significant.

These experimental results in a live roadway environment indicate that for the driver the mesopic adaptation model does not apply and no correction factors should be applied to the design of overhead lighting of roadways. 
Although this experiment did not find an effect of light source spectrum, it did address visual performance in the mesopic range. The detection differences among the adaptation luminance levels were in line with Adrian's model ${ }^{9}$ As adaptation luminance changed, so did contrast threshold. Comparing visibility level (VL) to Weber contrast (Figure 11) showed that as adaptation luminance increased, contrast decreased and VL increased. This is because higher adaptation luminances require higher threshold contrasts for object detection.

\section{Visibility Level and Weber Contrast by Adaptation Luminance}

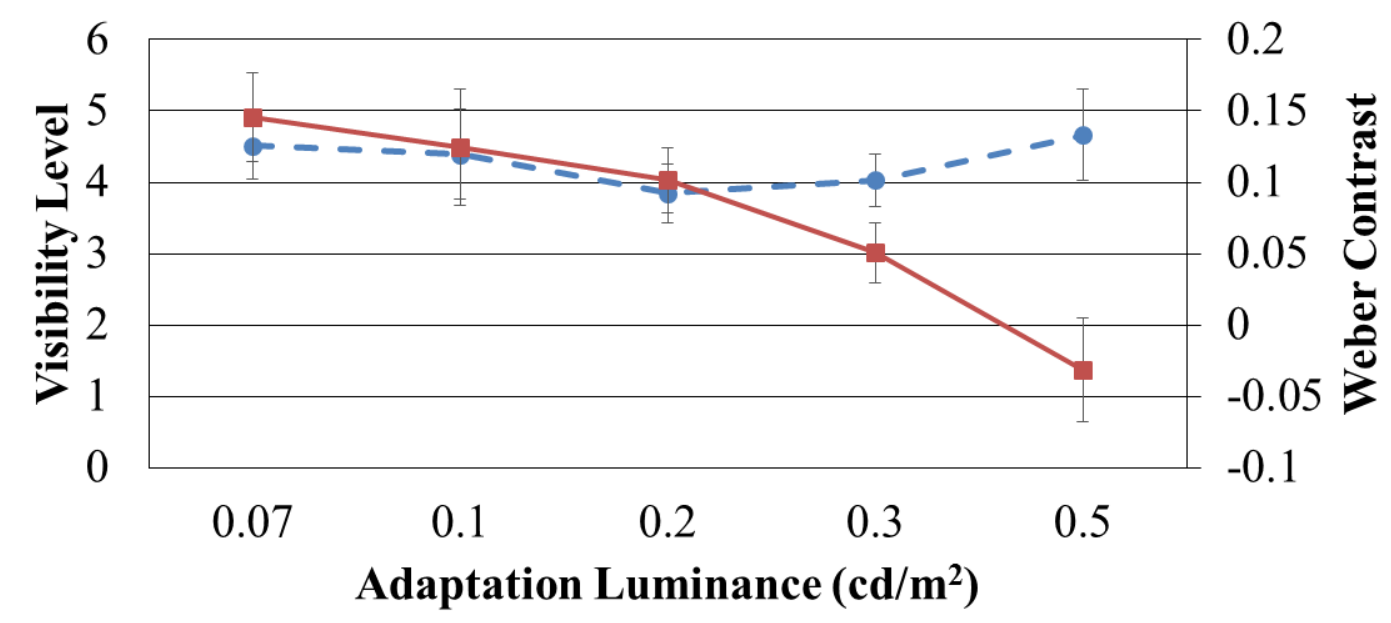

$-\bullet-$ Average VL $\rightarrow$ Average Contrast

Figure 11. Visibility level and Weber contrast plotted against adaptation luminance.

At the lowest adaptation luminance level, $0.07 \mathrm{~cd} / \mathrm{m}^{2}$, and at $14^{\circ}$ (corresponding

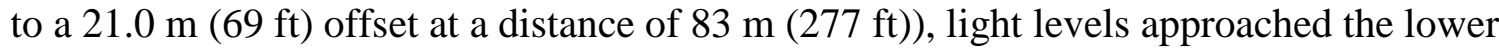
end of mesopic vision. The eye is more adapted to darkness and more contrast sensitive in those conditions, possibly causing the longer detection distances than those at 0.1 $\mathrm{cd} / \mathrm{m}^{2}$, where vision is more mesopic.

In general, visual performance depended more on adaptation luminance than on overhead lighting type. At higher adaptation luminances and closer to the photopic region, overhead lighting type had even less effect on visual performance. At the lowest adaptation luminance, mean detection distance was only about $10 \mathrm{~m}$ (30.5 ft.) shorter than at higher adaptation levels, likely because a dark-adapted eye is more contrast sensitive. The fact that detection distances were longer at the larger visual angles, where both pedestrians and background were darker, supports that conclusion. The $0.1 \mathrm{~cd} / \mathrm{m}^{2}$ adaptation luminance showed the shortest detection distances, and was the only adaptation luminance level where the pedestrian had positive contrast. The contrast of that adaptation level probably passed through zero as the vehicle approached the pedestrian, reducing the pedestrian's visibility. 
One of the important factors often neglected in the discussion of mesopic models is that the effect is peripheral only. It relies on the presence of rods, which are not present in the fovea. There was no difference in mean detection distances among the different lighting types for the pedestrians stationed closest to the roadway. For pedestrians at the $21.0 \mathrm{~m}$ (69 ft) offset, the two LED lighting types had longer detection distances than HPS, because the LED lighting had a greater scotopic to photopic $(\mathrm{S} / \mathrm{P})$ ratio and better spectral power distribution in the mesopic range. That result might have occurred only at the $21.0 \mathrm{~m}(69 \mathrm{ft})$ offset (corresponding to $14^{\circ}$ eccentricity at a distance of $83 \mathrm{~m}(277 \mathrm{ft})$ ), because the maximum rod density is at $15^{\circ}$ and is where a mesopic effect would most likely occur. However, without restricting the participants' eye-glance behavior, it is difficult to determine if detection occurred in the fovea or periphery.

\section{Conclusions}

The two objectives of this experiment were to (1) evaluate the impact of the spectra of overhead lighting systems on driver visual performance and (2) evaluate the applicability of mesopic models and scaling factors in a roadway lighting design.

The impact of the spectra of overhead lighting systems on off-axis visibility was minimal, as changes in lighting type did not affect detection distance significantly.

The inability to control where drivers were looking and what they are attending to at any given moment during a driving task makes predicting visibility of any roadway object difficult, especially those of low contrast. This limits the potential for a mesopic effect as many of the visual detections may have occurred foveally with no contribution of the rod photoreceptor. As such, the applicability of mesopic correction factors for the driver is limited

\section{Funding}

This project was sponsored by the United State Federal Highway Administration.

\section{References}

1. Commission Internationale de l'Eclairage, Recommended System for Mesopic Photometry Based on Visual Performance. CIE: Vienna, 2010.

2. Illuminating Engineering Society of North America. ANSI/IESNA TM-12 Spectral Effects of Lighting on Visual Performance at Mesopic Light Levels. New York: IESNA, 2014.

3. He Y, Bierman A, Rea M. A system of mesopic photometry. Lighting Research and Technology 1998; 30(4): 175-181.

4. Bullough JD, Rea M. Visual performance under mesopic conditions Consequences for roadway lighting. Proceedings of the Transportation Research 
Board 83 ${ }^{\text {rd }}$ Annual Meeting, Washington DC: Transportation Research Board: p.89-94.

5. Eloholma M, Viikari M, Halonen L, Walkey H, Goodman T, Alderdinck J, Freiding A, Bodrogi P, Varady G. Mesopic models - From brightness matching to visual performance in night-time driving: A review. Lighting Research and Technology 2005; 37(2): 155-175.

6. Rea M, Bullough JD, Freyssinier-Nova JP, Bierman A. A proposed unified system of photometry. Lighting Research and Technology 2004; 36(2): 81-111.

7. Helsinki University of Technology Lighting Laboratory, MOVE Mesopic Optimisation of Visual Efficiency: Performance Based Model for Mesopic Photometry, Espoo, Finland: HUT, 2005

8. Eloholma M, Halonen L. New model for mesopic photometry and its application to road lighting. Leukos 2006; 2(4): 263-293.

9. Adrian IW. Visibility of targets: Model for calculation. Lighting Research and Technology 1988, 21(4): 181-188.

\section{Figure captions}

Figure 12. Smart Road test track.

Figure 13. Pedestrian positions and offsets from the roadway.

Figure 14. Mean detection distance plotted against adaptation luminance. Errors bars denote standard error of the mean.

Figure 15. Mean detection distance plotted against adaptation luminance and offset. Error bars represent standard error. (Note: two conditions are missing due to limitation of the experiment environment).

Figure 16. Mean detection distance plotted against speed and offset. Error bars represent standard error of the mean.

Figure 17. Mean detection distance for the three way interaction of overhead lighting, speed and age. Error bars represent standard error of the mean.

Figure 18. Mean detection distance by offset and overhead lighting type. Error bars represent standard error.

Figure 19. Mean detection distance by adaptation luminance and overhead lighting type. Error bars represent standard error of the mean.

Figure 20. Mean detection distance and Weber contrast plotted against adaptation luminance. Error bars represent standard error of the mean.

Figure 21. Mean detection distance and Weber contrast plotted against offset. Error bars represent standard error of the mean. 
Figure 22. Visibility level and Weber contrast plotted against adaptation luminance. 
Table 1. Independent variables and values.

Independent Variable Levels

Age $\quad$ Younger (25-35), Older (65+) gender balanced

Overhead Lighting Type $\quad 2100$ K HPS, 3500 K LED, 6000 K LED

Adaptation Luminance $\left(\mathrm{cd} / \mathrm{m}^{2}\right) \quad 0.07,0.1,0.2,0.3,0.5$

\begin{tabular}{|c|c|}
\hline & 56 km/h (35 mph), 80 km/h (50 mph) \\
\hline
\end{tabular}

Offset $3.0,7.7,8.9,21.0 \mathrm{~m}(9.8,25,29,69 \mathrm{ft})$

Pedestrian on Left or Right Left, Right 
Table 2. Adaptation luminance for different combinations of overhead lighting level and pavement type.

\begin{tabular}{lll} 
Overhead Lighting Level & $\begin{array}{l}\text { Luminance on concrete } \\
\left(\mathbf{c d} / \mathbf{m}^{\mathbf{2}}\right)\end{array}$ & $\begin{array}{l}\text { Luminance on asphalt } \\
\left(\mathbf{c d} / \mathbf{m}^{2}\right)\end{array}$ \\
\hline Low & 0.11 & 0.07 \\
\hline Medium & $0.35^{*}$ & 0.20 \\
\hline High & 0.54 & $0.35^{*}$ \\
\hline
\end{tabular}


Table 3. Participant characteristics.

\begin{tabular}{lllll} 
Participant & $\begin{array}{l}\text { Older } \\
\text { Drivers }\end{array}$ & $\begin{array}{l}\text { Older } \\
\text { Drivers }\end{array}$ & $\begin{array}{l}\text { Young } \\
\text { Drivers }\end{array}$ & $\begin{array}{l}\text { Younger } \\
\text { Drivers }\end{array}$ \\
Characteristic & Mean & $\begin{array}{l}\text { Standard } \\
\text { Deviation }\end{array}$ & Mean & $\begin{array}{l}\text { Standard } \\
\text { Deviation }\end{array}$ \\
\hline Age & 70.4 & 6.3 & 30.5 & 3.2 \\
\hline Visual Acuity & $20 / 21.6$ & 5.25 & $20 / 17.3$ & 3.53 \\
\hline Mesopic Visual Acuity & $20 / 38.1$ & 13.5 & $20 / 25.8$ & 6.4 \\
\hline Low-contrast Visual Acuity & $20 / 27.8$ & 7.3 & $20 / 20.9$ & 5.3 \\
\hline
\end{tabular}


Table 4. Statistically significant results for ANOVA for detection distance.

\begin{tabular}{lll} 
Independent Variable & $\begin{array}{l}\text { Detection } \\
\text { Distance } \\
\boldsymbol{F}\end{array}$ & $\begin{array}{l}\text { Detection } \\
\text { Distance } \\
\boldsymbol{p}\end{array}$ \\
\hline Adaptation Luminance & 8.26 & $<0.0001$ \\
\hline Age & 7.16 & 0.0119 \\
\hline Offset $\times$ Adaptation Luminance & 7.69 & $<0.0001$ \\
\hline Offset $\times$ Speed & 3.96 & 0.0114 \\
\hline Offset $\times$ Adaptation Luminance $\times$ Speed & 2.33 & 0.0123 \\
\hline Offset $\times$ Age $\times$ Adaptation Luminance & 2.23 & 0.0172 \\
\hline Overhead Lighting Type $\times$ Age $\times$ Speed & 3.68 & 0.0356 \\
\hline
\end{tabular}


Table 5. Statistically significant results for ANCOVA for detection distance with contrast as covariate.

\section{Detection Detection}

Distance Distance

Factor(s)

Adaptation Luminance

Offset $\times$ Adaptation Luminance

\section{F $\quad \boldsymbol{p}$}

$8.46<0.0001$

$6.57<0.0001$

